\title{
Quality of Life Experienced by Adolescents and Young Adults With Congenital Heart Disease
}

\author{
Flávio Miguel Teixeira $\cdot$ Rosália Maria Coelho Cidália Proença $\cdot$ \\ Ana Margarida Silva $\cdot$ Daniela Vieira $\cdot$ Cláudia Vaz Cláudia Moura • \\ Victor Viana · José Carlos Areias · Maria Emília Guimarães Areias
}

Received: 9 February 2011/Accepted: 16 June 2011/Published online: 28 June 2011

(C) Springer Science+Business Media, LLC 2011

\begin{abstract}
This study aimed to assess the quality of life (QOL) experienced by adolescents and young adults with congenital heart disease (CHD) and to determine which factors negatively affect adjustment and which factors increase resilience. The participants in the study were 74 patients with CHD (41 males and 33 females) ranging in age from 12 to 26 years (mean age, $18.76 \pm 3.86$ years). Demographic information and a complete clinical history were obtained. The participants were interviewed regarding topics such as social support, family educational style, selfimage, and physical limitations. They responded to questions in a standardized psychiatric interview (SADS-L) and
\end{abstract}

F. M. Teixeira $\cdot$ R. M. Coelho $\cdot$ C. Proença .

A. M. Silva · D. Vieira · C. Vaz · M. E. G. Areias ( $\square)$

Department of Psychology, Instituto Superior de Ciências da

Saúde do Norte (CESPU), Rua Central de Gandra 1317,

585-116 Gandra PRD, Portugal

e-mail: metega@netcabo.pt

C. Moura $\cdot$ V. Viana · J. C. Areias

Department of Paediatrics (Cardiology), Hospital São João Porto

Medical School, University of Porto, Porto, Portugal

M. E. G. Areias

CINEICC Centro de Investigação do Núcleo de Estudos e

Intervenção Cognitivo-Comportamental, Coimbra, Portugal

F. M. Teixeira $\cdot$ R. M. Coelho · C. Proença ·

A. M. Silva - D. Vieira - C. Vaz

UNIPSA Unidade de Investigação de Psicologia e Saúde,

Gandra, Portugal

C. Moura - J. C. Areias

Unidade de Investigação Cardiovascular, Porto, Portugal

V. Viana

Faculty of Nutrition, University of Porto, Porto, Portugal completed a self-report questionnaire (WHOQOL-BREF) for assessment of QOL. Compared with the Portuguese population as a whole, the study patients had better QOL, especially with regard to the environmental dimension $(t=3.754 ; P=0.000)$ and social relationships $(t=2.333$; $P=0.022)$. Patients who had undergone surgery experienced poorer QOL in the physical dimension $(t=-1.989$; $P=0.050)$, in social relationships $(t=-2.012 ; P=$ 0.048) and overall (Mann-Whitney $U=563.000 ; P=$ 0.037). Social support played a positive role in the QOL of the patients, both in the physical dimension $(t=3.287$; $P=0.002)$ and in social relationships $(t=3.669 ; P=$ $0.000)$. A higher school achievement also was associated with higher levels of QOL overall (Mann-Whitney $U=457.000 ; P=0.046)$ as well as in the physical $(t=2.045 ; \quad P=0.045)$ and environmental $(t=2.413$; $P=0.018)$ dimensions. Physical limitations had a detrimental impact on general QOL (Mann-Whitney $U=$ 947.500; $P=0.001)$ and on the physical $(t=-2.910$; $p=0.005)$ and psychological $(t=-2,046 ; P=0.044)$ dimensions. Patients with CHD tended to perceive QOL as better when their social networks were supportive.

Keywords Congenital heart disease - Quality of life · Social support

Congenital heart disease (CHD) is defined as a malformation of the heart or the large blood vessels that develops during the fetal period. Clinically, it is classified as cyanotic or acyanotic based on the gradient of oxygen saturation in the blood [17].

Recent progress in early diagnosis and treatment has increased the life expectancy of patients with CHD. Currently, $90 \%$ of newborns with a diagnosis of CHD live to 
adulthood, and this population is increasing at the rate of approximately $5 \%$ per year $[2,3,10]$.

As survival rates improve, psychosocial issues have emerged as a critical research area. A prominent clinical concern is patient perception of quality of life (QOL) [13].

Over the past few decades in most developed countries, chronic illnesses have become more frequent and important than acute and infectious diseases. This shift has generated interest in the concepts of QOL and health-related QOL (HRQOL), which have been widely explored. As a multidimensional construct, QOL includes physical, cognitive, social, and emotional dimensions. Because QOL changes over time, it is dynamic rather than fixed. The more specialized concept of HRQOL, conceptualized as the impact of an illness or medical treatment on QOL, is particularly relevant for CHD patients [4, 7, 9].

To date, studies of QOL among CHD patients have reported contradictory findings. Some studies have reported that poorer QOL is related to cardiac instability [15], greater disease severity [8, 12], and poorer motor functioning and autonomy [11], although no differences were found for the variables of gender, age, and marital status [15]. Some studies have found poorer psychological wellbeing and QOL in CHD patients than in healthy control subjects $[18,19]$, whereas others have claimed there is no difference between the two groups. Some researchers have reported that the congenital nature of the disease leads CHD patients to have better QOL than healthy individuals $[5,16]$.

Our study makes a significant contribution by systematically investigating QOL in different subgroups of patients and by examining its association with clinical and psychosocial factors that enhance and diminish patient resilience.

\section{Materials and Methods}

\section{Participants}

The study enrolled 74 CHD patients (41 males and 33 females) with a mean age of $18.76 \pm 3.86$ years (range, 12-26 years). The participants who had not achieved an educational level that enabled them to understand and complete the written questionnaires were excluded from the study.

At the time of the study, two participants were married, one was divorced, and two were living in a marital union. All the other participants were single. Of the 74 participants, 20 were employed full- or part-time, 6 were unemployed, and all the others were students. With regard to educational level, 9 participants had completed the second cycle (the first cycle of the Portuguese school system includes the 4 years of primary school; the second cycle includes grades 5 and 6), 27 had completed the third cycle (grades 7, 8, and 9), 33 had a secondary education (grades 10,11 , and 12), and 5 had a university degree. About half of the participants $(n=38)$ had been held back in school for an average of $1.74 \pm 0.86$ years.

Complete medical records were available for all the patients, who had been followed in the pediatric cardiology or cardiology departments of a tertiary hospital. For 45 individuals, the congenital cardiac malformation was cyanotic, and for 29 patients, it was acyanotic. According to clinical files, at the time of diagnosis, 27 participants exhibited a severe form of CHD, 13 had a moderate form, and 34 had a mild form. Whereas 31 participants were physically limited to some extent, 43 participants experienced no physical limitations. In terms of disease severity, 4 participants had severe residual lesions, 18 had moderate residual lesions, and 52 had mild residual lesions.

For several participants, the main CHD was combined with other heart diseases. Individuals with associated extra cardiac malformations or chromosomopathies were excluded from the study.

The participants exhibited the following distribution of pathologies: transposition of the great arteries (8 patients: additionally, 4 of these patients had ventricular septal defect, 1 had aortic stenosis, 1 had pulmonary stenosis, and 2 had coarctation of the aorta), tetralogy of Fallot (26 patients), coarctation of the aorta (4 patients besides the 2 noted earlier), ventricular septal defect (10 patients: additionally, 1 of these patients had interrupted aortic arch and 1 had mitral insufficiency), atrial septal defect (6 patients: additionally, 1 of these patients had mitral atresia and pulmonary hypertension), atrioventricular septal defect (2 patients), aortic stenosis (1 patient), pulmonary stenosis (6 patients), single ventricle ( 2 patients: additionally, 1 of these patients had pulmonary atresia, and 1 had pulmonary stenosis), patent ductus arteriosus (2 patients), double-outlet right ventricle (1 patient), Ebstein anomaly (3 patients), and pulmonary atresia (3 patients).

The diagnosis was determined during the neonatal period for 40 of the participants, before the first birthday for 28 , between the ages of 1 and 3 years for 3 , and between the ages of 3 and 6 years for 3 of the participants.

The first surgery was performed for 2 of the participants during the neonatal period, before the first birthday for 24 , between the ages of 1 and 3 years for 15, between the ages of 3 and 6 years for 16, and between the ages of 6 and 12 years for 3 of the participants.

One or more of the following psychiatric disorders had been diagnosed for 17 of the participants (23\%) before the interview: minor or major depressive syndrome $(n=11)$, panic disorder $(n=2)$, anxiety disorder $(n=2)$, or manic syndrome $(n=1)$, and cyclothymic personality $(n=1)$. 
Assessment Instruments

The patients were interviewed on only one occasion. A questionnaire was used to collect a complete clinical history (e.g., diagnosis, severity and category of CHD, course of illness, surgeries, presence of residual lesions, and treatment with medication) and demographic information (e.g., marital status, educational level, and occupation). The participants took part in a semistructured interview covering topics such as social support, family educational style, environment, self-image, functional limitations, educational background, and emotional adjustment.

A standardized psychiatric interview using the Schedule for Affective Disorders and Schizophrenia-Lifetime (SADS-L) was administered to obtain a clinical diagnosis of any psychopathologic disorders that may have existed before the interview. The participants completed a selfreport questionnaire (WHOQOL-BREF) for assessment of their QOL. Additional questionnaires used in this research are described in detail in another report.

The semistructured interview included 38 multiplechoice and short-answer questions that focused on the personal circumstances of each patient and how $\mathrm{CHD}$ affected different aspects of his or her daily life.

The WHOQOL-BREF is a self-report questionnaire that assesses subjective QOL in both healthy individuals and those with wide range of psychological and physical disorders. It is a 26-item Likert-type scale with ratings from 1 to 5. For almost all the scale items, higher scores reflect a higher QOL. However, for three items (questions 3, 4, and 26), higher scores reflect a lower QOL. The first two questions of the instrument assess general QOL.

The WHOQOL-BREF also assesses four dimensions of QOL: physical (questions 3, 4, 10, 15, 16, 17, and 18), psychological (questions 5, 6, 7, 11, 19, and 26), social (questions 20, 21, and 22), and environmental (questions 8, $9,12,13,14,23,24$, and 25). The environmental scale includes topics on physical security, home environment, financial resources, opportunities to acquire new information and abilities, availability of health care, physical environment, and transportation. For each dimension, the average score is calculated and transformed into a scale value that ranges from 0 to 100 .

\section{Procedure}

Prospective participants were contacted before or after scheduled hospital appointments. After the purposes and procedures of the investigation had been explained, they were asked to participate. Those who agreed completed an informed consent form approved by the hospital's ethical committee, which followed international conventions guaranteeing the rights of the patients.
Design

All the assessment measures were obtained on a single occasion. Clinical data were collected retrospectively using each patient's clinical record, with assistance from hospital medical staff.

Data Analysis

Statistical analyses of the data were performed using the IBM Social Package for the Social Sciences (SPSS), version 19.0 (SPSS, Chicago, IL, USA). The distribution of all the variables was tested. Differences for parametric variables were established using Student's $t$-tests, and differences for nonparametric variables were established using Mann-Whitney $U$ tests and Chi-square tests of association.

\section{Results}

Table 1 presents the QOL scores of the participants for each QOL dimension and comparable scores for the Portuguese population as a whole. The participants had higher QOL scores than the overall population [21] in the areas of social relationships and environmental dimension.

No significant differences in QOL scores were related to the factors of gender, age, CHD subtype, or severity of the illness. The difference in QOL scores approached significance for severity of residual lesions at the 0.055 level of significance, which suggests a tendency for patients with mild residual lesions to have better QOL in the physical dimension than the group with moderate or severe residual lesions (Table 2).

With regard to the need for treatment with medication, the patients without medication had better QOL in the area of social relationships (Table 3). The patients who had not undergone surgery had better QOL both overall and in the physical and social dimensions (Table 4). However, there was no significant difference in perception of QOL between those who had only one surgery and those who had two or more surgeries.

Social support has a relevant impact on QOL. The patients with better social support had better QOL in general and across all dimensions (Table 5). The female participants reported greater social support than the male participants (Table 6).

Compared with the patients with physical limitations, those who were satisfied with their physical abilities had better QOL overall and in the physical and psychological dimensions (Table 7).

Furthermore, the patients with better academic performance had better QOL overall and in the physical and environmental dimensions than those reporting poor 
Table 1 Results of Student's $t$ tests and Mann-Whitney $U$ tests of QOL for participants compared with those of the Portuguese population as a whole

\begin{tabular}{|c|c|c|c|c|c|c|}
\hline \multirow[t]{2}{*}{ QOL dimension } & \multicolumn{2}{|l|}{ RV } & \multicolumn{2}{|c|}{ Study participants } & \multirow[t]{2}{*}{$t$ value } & \multirow[t]{2}{*}{$P$ value } \\
\hline & Mean & SD & Mean & SD & & \\
\hline Physical & 77.49 & 12.27 & 75.29 & 13.516 & -1.400 & 0.166 \\
\hline Psychological & 72.38 & 13.50 & 73.34 & 13.924 & 0.590 & 0.557 \\
\hline Social relationships & 70.42 & 14.54 & 74.91 & 16.573 & 2.333 & 0.022 \\
\hline Environment & 64.89 & 12.24 & 70.65 & 13.209 & 3.754 & 0.000 \\
\hline General QOL & 71.51 & 13.30 & 72.47 & 15.89 & 0.518 & 0.606 \\
\hline
\end{tabular}

$Q O L$ quality of life, $R V$ reference value for the Portuguese population as a whole [21], $S D$ standard deviation

Table 2 Results of Student's $t$ tests and Mann-Whitney $U$ tests of QOL for groups with different residual lesion (RL) severities

\begin{tabular}{|c|c|c|c|c|c|c|c|}
\hline \multirow[t]{2}{*}{ QOL dimension } & \multicolumn{2}{|c|}{ Severe or moderate RL $(n=23)$} & & \multicolumn{2}{|c|}{ Mild RL $(n=51)$} & \multirow[t]{2}{*}{$t$ value } & \multirow[t]{2}{*}{$P$ value } \\
\hline & Mean & SD & & Mean & SD & & \\
\hline Physical & 15.33 & 2.410 & & 16.37 & 1.982 & -1.952 & 0.055 \\
\hline Psychological & 15.23 & 2.460 & & 15.91 & 2.108 & -1.207 & 0.231 \\
\hline Social relationships & 16.12 & 2.746 & & 15.92 & 2.629 & 0.290 & 0.772 \\
\hline \multirow[t]{2}{*}{ Environment } & 15.07 & 2.488 & & 15.41 & 1.943 & -0.638 & 0.526 \\
\hline & \multicolumn{2}{|c|}{ Mean } & Mean & \multicolumn{3}{|c|}{$U$ value } & $P$ value \\
\hline General QOL & \multicolumn{2}{|c|}{33.70} & 39.22 & \multicolumn{3}{|c|}{674.000} & 0.280 \\
\hline
\end{tabular}

$Q O L$ quality of life, $S D$ standard deviation

Table 3 Results of Student's $t$ tests and Mann-Whitney $U$ tests of QOL for groups with and without the need for medication

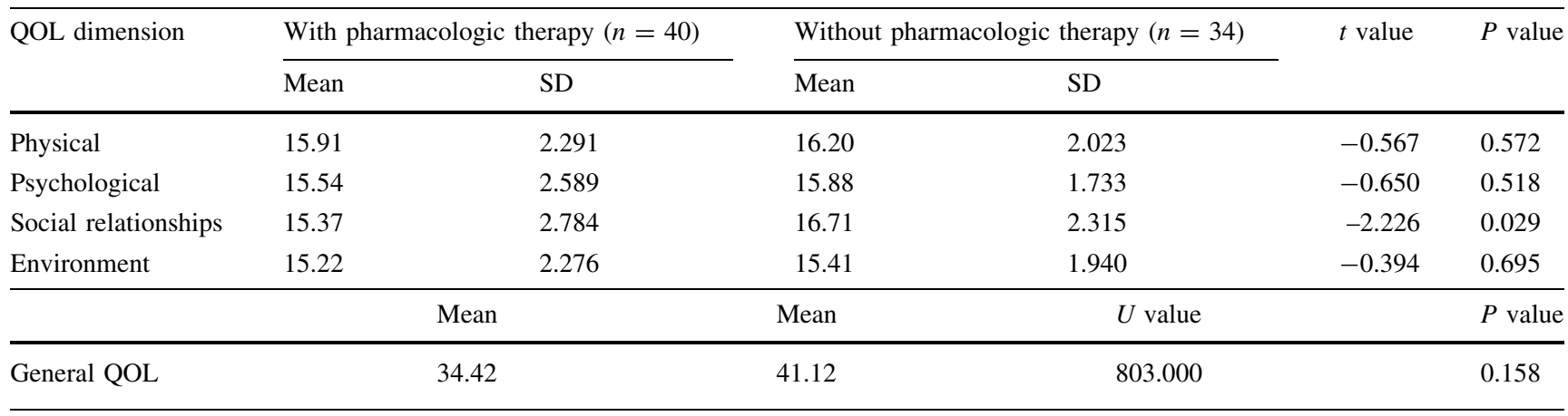

$Q O L$ quality of life, $S D$ standard deviation

Table 4 Results of Student's $t$ tests and Mann-Whitney $U$ tests of QOL for groups with and without surgery

\begin{tabular}{|c|c|c|c|c|c|c|}
\hline \multirow[t]{2}{*}{ QOL dimension } & \multicolumn{2}{|c|}{ With surgery $(n=60)$} & \multicolumn{2}{|c|}{ Without surgery $(n=14)$} & \multirow[t]{2}{*}{$T$ value } & \multirow[t]{2}{*}{$P$ value } \\
\hline & Mean & SD & Mean & SD & & \\
\hline Physical & 15.81 & 2.224 & 17.06 & 1.567 & -1.989 & 0.050 \\
\hline Psychological & 15.46 & 2.304 & 16.71 & 1.557 & -1.928 & 0.058 \\
\hline Social relationships & 15.69 & 2.634 & 17.24 & 2.409 & -2.012 & 0.048 \\
\hline \multirow[t]{2}{*}{ Environment } & 15.14 & 2.207 & 16.04 & 1.525 & -1.443 & 0.153 \\
\hline & \multicolumn{2}{|c|}{ Mean } & Mean & \multicolumn{2}{|c|}{$U$ value } & $P$ value \\
\hline General QOL & \multicolumn{2}{|c|}{35.12} & 47.71 & \multicolumn{2}{|c|}{563.000} & 0.037 \\
\hline
\end{tabular}

$Q O L$ quality of life, $S D$ standard deviation 
Table 5 Results of Student's $t$ tests and Mann-Whitney $U$ tests of QOL for groups differing in degree of social support

\begin{tabular}{|c|c|c|c|c|c|c|}
\hline \multirow[t]{2}{*}{ QOL dimension } & \multicolumn{2}{|c|}{ More social support $(n=54)$} & \multicolumn{2}{|c|}{ Less social support $(n=20)$} & \multirow[t]{2}{*}{$t$ value } & \multirow[t]{2}{*}{$P$ value } \\
\hline & Mean & SD & Mean & SD & & \\
\hline Physical & 16.52 & 2.011 & 14.77 & 2.083 & 3.287 & 0.002 \\
\hline Psychological & 16.16 & 2.167 & 14.45 & 1.935 & 3.094 & 0.003 \\
\hline Social Relationships & 16.62 & 2.143 & 14.27 & 3.145 & 3.669 & 0.000 \\
\hline \multirow[t]{2}{*}{ Environment } & 15.70 & 1.901 & 14.25 & 2.348 & 2.725 & 0.008 \\
\hline & \multicolumn{2}{|c|}{ Mean } & Mean & \multicolumn{2}{|l|}{$U$ value } & $P$ value \\
\hline General QOL & \multicolumn{2}{|c|}{41.52} & 26.65 & \multicolumn{2}{|l|}{323.000} & 0.005 \\
\hline
\end{tabular}

$Q O L$ quality of life, $S D$ standard deviation

Table 6 Results of a Chi-square test of association between gender and degree of social support

\begin{tabular}{|c|c|c|c|c|c|c|}
\hline & \multicolumn{2}{|c|}{ More social support $(n=54)$} & \multicolumn{2}{|c|}{ Less social support $(n=20)$} & \multirow[t]{2}{*}{$\chi^{2}$} & \multirow[t]{2}{*}{$P$ value } \\
\hline & $n$ & $\%$ & $n$ & $\%$ & & \\
\hline Males & 25 & 61.0 & 16 & 39.0 & 6.71 & 0.017 \\
\hline Females & 29 & 87.9 & 4 & 12.1 & & \\
\hline
\end{tabular}

Table 7 Results of Student's $t$ tests and Mann-Whitney $U$ tests of QOL for groups differing in physical limitations

\begin{tabular}{|c|c|c|c|c|c|c|}
\hline \multirow[t]{2}{*}{ QOL dimension } & \multicolumn{2}{|c|}{ With physical limitations $(n=31)$} & \multicolumn{2}{|c|}{ Without physical limitations $(n=43)$} & \multirow[t]{2}{*}{$T$ value } & \multirow[t]{2}{*}{$P$ value } \\
\hline & Mean & SD & Mean & SD & & \\
\hline Physical & 15.23 & 2.141 & 16.64 & 2.000 & -2.910 & 0.005 \\
\hline Psychological & 15.09 & 1.908 & 16.14 & 2.357 & -2.046 & 0.044 \\
\hline Social Relationships & 15.61 & 2.753 & 16.25 & 2.570 & -1.018 & 0.312 \\
\hline \multirow[t]{2}{*}{ Environment } & 14.79 & 2.113 & 15.68 & 2.064 & -1.807 & 0.075 \\
\hline & \multicolumn{2}{|c|}{ Mean } & Mean & $U$ value & & $P$ value \\
\hline General QOL & \multicolumn{2}{|c|}{28.44} & 44.03 & 947.500 & & 0.001 \\
\hline
\end{tabular}

$Q O L$ quality of life, $S D$ standard deviation

Table 8 Results of Student's $t$ tests and Man-Whitney $U$ tests of QOL for groups with different levels of academic performance

\begin{tabular}{|c|c|c|c|c|c|c|}
\hline \multirow[t]{2}{*}{ QOL dimension } & \multicolumn{2}{|c|}{ Better academic performance $(n=48)$} & \multicolumn{2}{|c|}{ Poorer academic performance $(n=26)$} & \multirow[t]{2}{*}{$t$ value } & \multirow[t]{2}{*}{$P$ value } \\
\hline & Mean & SD & Mean & SD & & \\
\hline Physical & 16.42 & 2.192 & 15.36 & 1.968 & 2.045 & 0.045 \\
\hline Psychological & 16.06 & 2.218 & 15.03 & 2.127 & 1.950 & 0.055 \\
\hline Social Relationships & 16.15 & 2.327 & 15.67 & 3.185 & 0.752 & 0.455 \\
\hline \multirow[t]{2}{*}{ Environment } & 15.73 & 2.210 & 14.52 & 1.708 & 2.413 & 0.018 \\
\hline & \multicolumn{2}{|c|}{ Mean } & Mean & $U$ value & & $P$ value \\
\hline General QOL & \multicolumn{2}{|c|}{40.98} & 31.08 & 457.000 & & 0.046 \\
\hline
\end{tabular}

$Q O L$ quality of life, $S D$ standard deviation 
academic performance. The difference between these two groups with respect to the psychological dimension of QOL also approached significance (Table 8).

\section{Discussion}

This study is important because it systematically tested the effects of different demographic, clinical, and psychosocial variables on the perception of QOL in CHD patients. To our knowledge, no other published report includes all these variables, highlighting the relevance of this study to the goal of assisting individuals with CHD, a group that is rapidly increasing worldwide.

To determine the extent to which these factors enhanced resilience or had a detrimental effect on individuals with CHD, we analyzed factors such as severity of illness, number of surgeries, presence of residual lesions, presence of cyanosis, occurrence of psychopathologic disorders, education and academic achievement, size and functioning of the social support network, and physical abilities and limitations. We found that CHD patients had a better QOL than the Portuguese population overall in terms of environmental and social dimensions.

Several prior studies also reported better QOL in CHD patients than in the population as a whole $[5,16]$. This intriguing result may be due to the fact that for individuals with CHD, coping with the disease fosters adaptation and resilience from an early age. Human beings tend to think in comparative terms. If they experience the development of a chronic disease later in life, they compare this unexpected new situation to a previous life without illness. However, most CHD patients have been aware of the illness and its limitations for as long as they can remember. It is their parents who had to adapt to any turmoil caused by the illness (sometimes even before the patient was born if the diagnosis was prenatal). In addition, the fact that these patients require a significant amount of additional care may promote a protective and cohesive family environment, which may reduce stress and foster positive adaptation.

Surprisingly, comparison of patient subgroups showed that neither the severity of illness nor the presence of cyanosis had an impact on QOL. Ternested et al. [20] reported similar findings.

However, surgery, the need for medication, the severity of residual lesions, and the existence of physical limitations all had a negative impact on QOL. On the other hand, greater social support and better academic performance seemed to play a positive role in adaptation and life satisfaction.

Patients who had undergone surgery reported poorer QOL than those who did not have surgery. This may be the case because surgery and hospitalization commonly result in restrictions in daily life and limitations in physical activity. Patients who undergo surgery also may experience pain and discomfort more often and see themselves as more fragile.

Many patients experience physical difficulties at times (e.g., breathlessness, fatigue, pain, dizziness, and fainting), particularly during physical exercises such as running or climbing stairs [1]. Consequently, they may feel excluded from activities involving intense effort. Although feelings of exclusion may result from a lack of stamina, they also may be due to the beliefs and behaviors of others toward the patients. Individuals with CHD are more likely to be excluded from activities that require social interaction, such as sports, work or other activities, when others are overprotective. This can lead to feelings of helplessness in patients that are related to observable physical symptoms $[5,6,14]$. This may explain why individuals with fewer physical limitations perceive their QOL as better than those whose physical activities are more restricted.

Social support showed a huge impact on the QOL of patients because those with better social support showed better QOL in all dimensions than those with poorer social support. The amount of social support and the perceptions of individuals about it seem to play an important mediating and buffering role for stress impact, protecting psychological well-being [22, 23].

Individuals with higher levels of academic achievement reported better QOL overall and in the physical and environmental dimensions. School performance can be markedly affected by CHD. Hospitalization and restrictions on activities with friends and fellow students make successful performance in school more difficult, especially if the individual is absent for long periods. Moreover, individuals with CHD experience frequent fatigue, leading to increased difficulty in paying attention during class as the day progresses $[1,17]$. Having a poorer school performance can be a barrier to successful employment, and many employers may be reluctant to hire a worker who may have physical limitations [3-5].

Acknowledgment This research was supported by a grant from the Instituto Superior de Ciências da Saúde do Norte (CESPU).

\section{References}

1. Birks Y, Sloper P, Lewin R, Parsons J (2006) Exploring healthrelated experiences of children and young people with congenital heart disease. Health Expect 10:16-29

2. Brickner M, Hillis L, Lange R (2000) Congenital heart disease in adults: first of two parts. N Engl J Med 342:256-263

3. Claessens P, Moons P, Casterlé B, Cannaerts N, Budts W, Gewilling M (2005) What does it mean to live with a congenital heart disease? A qualitative study on the lived experiences of adult patients. Eur J Cardiovasc Nurs 4:3-10 
4. Daliento L, Mapelli D, Volpe B (2006) Measurement of cognitive outcome and quality of life in congenital heart disease. Heart 92:569-574

5. Fekkes M, Kamphuis R, Ottenkamp J, Verrips E, Vogels T, Kamphuis M, Verloove-Vanhorick S (2001) Health-related quality of life in young adults with minor congenital heart disease. Psychol Health 16:239-250

6. Foster E, Driscoll D, Russel I, Usark K (2001) Task force 2: special health care needs of adults with congenital heart disease. JACC 31:1161-1198

7. Goldbeck L, Melches J (2005) Quality of life in families of children with congenital heart disease. Qual Life Res 14:1915-1924

8. Goldbeck L, Melches J (2006) The impact of the severity of disease and social disadvantage on quality of life in families with congenital cardiac disease. Cardiol Young 16:67-75

9. Grootenhuis M, Koopman H, Verrips E, Vogels A, Last B (2007) Health-related quality of life problems of children aged 8-11 years with a chronic disease. Dev Neurorehab 10:27-33

10. Hoffman J, Kaplan S (2002) The incidence of congenital heart disease. J Am Coll Cardiol 39:1890-1900

11. Krol Y, Grootenhuis M, Destrée-Vonk A, Lubbers L, Koopman H, Last B (2003) Health-related quality of life in children with congenital heart disease. Psychol Health 18:251-260

12. Latal B, Helfricht S, Fischer J, Bauersfeld U, Landolt M (2009) Psychological adjustment and quality of life in children and adolescents following open-heart surgery for congenital heart disease: a systematic review. BMC Pediatr 9:1-10

13. Loup O, Weissenfluh C, Gahl B, Schwerzmann M, Carrel T, Kadner A (2009) Quality of life of grown-up congenital heart disease patients after congenital cardiac surgery. Eur J Cardiothorac Surg 36:105-111

14. McMurray R, Kendall L, Parsons J, Quirk J, Veldtman G, Lewin R, Sloper P (2001) A life less ordinary: growing up and coping with congenital heart disease. Coronary Health Care 5:51-57
15. Moons P, Deyk K, Marquet K, Bleser L, Geest S, Budts W (2009) Profile of adults with congenital heart disease having a good, moderate, or poor quality of life: a cluster analytic study. Eur J Cardiovasc Nurs 8:151-157

16. Moons P, Deyk K, Marquet K, Raes E, Bleser L, Budts W, Geest $S$ (2005) Individual quality of life in adults with congenital heart disease: a paradigm shift. Eur Heart J 26:298-307

17. Nousi D, Christou A (2010) Factors affecting the quality of life in children with congenital heart disease. Health Sci J 4:94-100

18. Rose M, Köhler K, Köhler F, Sawitzky B, Fliege H, Klapp B (2005) Determinants of quality of life of patients with congenital heart disease. Qual Life Res 14:35-43

19. Spijkerboer A, Utens E, De Koning W, Bogers A, Helbing W, Verhulst F (2006) Health-related quality of life in children and adolescents after invasive treatment for congenital heart disease. Qual Life Res 15:663-673

20. Ternested BM, Wall K, Oddsson H, Riesenfeld T, Grith I, Schollin J (2001) Quality of life 20 and 30 years after surgery in patients operated on for tetralogy of Fallot and for atrial septal defect. Pediatr Cardiol 22:128-132

21. Vaz Serra A, Canavarro M, Simões M, Pereira M, Gameiro S, Quartilho M, Rijo D, Carona C, Paredes T (2006) Estudos psicométricos do instrumento de avaliação da Qualidade de Vida da Organização Mundial de Saúde (WHOQOL-Bref) para Português de Portugal. Psiquiatria Clínica 27:41-49

22. Tak YR, McCubbin M (2002) Family stress, perceived social support, and coping following the diagnosis of a child's congenital heart disease. J Adv Nurs 39:190-198

23. van Rijen E, Utens E, Ross-Hesselink J, Meijboom F, van Domburg R, Roelandt J, Verhulst F (2004) Styles of coping and social support in a cohort of adults with congenital heart disease. Cardiol Young 14:122-130 